\title{
Preface to Special Issue on Celebrating the 70th Anniversary of Dalian Institute of Chemical Physics, Chinese Academy of Sciences
}

The 70th anniversary of Dalian Institute of Chemical Physics (DICP), Chinese Academy of Sciences (CAS), has been celebrating in various ways through the year of 2019. DICP was established with the name of Scientific Research Institute of Dalian University on March 19, 1949, which is even a little earlier than the foundation of the People's Republic of China (October 1, 1949). Since then, the name of the institute has changed several times in order to fulfill the assigned regional and national research mission. In 1970, the institute was named as the "Dalian Institute of Chemical Physics, Chinese Academy of Sciences".

Since its foundation, DICP has been at the forefront of fundamental and applied sciences and technologies that closely response the scientific and economic demands of China. After the continuous efforts of several generations, DICP has gained a high reputation in chemistry research, covering from fundamental studies, technology development to industrial applications. DICP conducts research mainly in catalytic chemistry, chemical engineering, chemical lasers, molecular reaction dynamics, organic chemistry, analytical chemistry, biotechnology, etc. Especially, DICP has made great contributions in the field of catalysis. The most prominent fundamental reseach activities in catalysis include heterogeneous catalysis, such as zeolitic catalysis, supported metal catalysis, nano to single-atom catalysis, and metal oxide catalysis together with homogeneous catalysis mainly based on organometallic catalysis, molecular catalysis, and some enzyme catalysis and biomimetic catalysis. In the last decade, photocatalysis, photoelectrocatalysis and electrocatalysis have become active, shifting from the catalysis for fossil resource conversion to that for renewable energy development and artificial photosynthesis. DICP is also recognized for the industrialization of its basic research such as industrialization of methanol to olefins (DMTO) technology, fuel cells and flow batteries for energy conversion and storages. These investigations have contributed to the development of science, technology and the growth of the national economy in China.

To promote the international cooperation, DICP has established strong relations/collaborations with the leading catalysis institutions in the world. Many faculties in DICP have been actively participating in the international catalysis communities, serving as important roles in catalysis societies both in China and in the world. DICP has been also active in scholar exchanges for international collaborations by recruiting foreign scholars and students as well as sending its staffs and students abroad. Furthermore, DICP has built up close collaboration with world leading chemcial industrial companies, such as General Motors, Corning, TOTAL, UOP, ADM, Eli Lilly, Invista, BP, BASF, BAYER, SAMSUNG, LG, TOPSOE, ITOCHU, SABIC, etc., and has built up joint research laboratories, such as the Sino-Franco Joint Catalysis Laboratory, BP-DICP EIL laboratories, etc.

To meet the increasing demand for clean and renewable energy, DICP now focuses its research on clean energy conversion, storage and utilization. The institute strives to provide cutting-edge theories and technologies for efficient conversion and utilization of fossil fuels, and development of renewable energy conversion. Hence, the catalysis research is defined as the flagship research areas at DICP.

To celebrate the 70th anniversary of DICP, the Chinese Journal of Catalysis publishes this special issue. Internationally renowned catalysis scientists were kindly invited to make contributions. The special issue contains twenty-three papers, including two Editorials, three Reviews, one Communication, and seventeen research Articles that cover aspects of both fundamental studies and industrial applications.

DOI: S1872-2067(19)63457-1 | http://www.sciencedirect.com/science/journal/18722067 | Chin. J. Catal., Vol. 40, No. 11, November 2019 (C) 2019, Dalian Institute of Chemical Physics, Chinese Academy of Sciences. Published by Elsevier B.V. All rights reserved. 


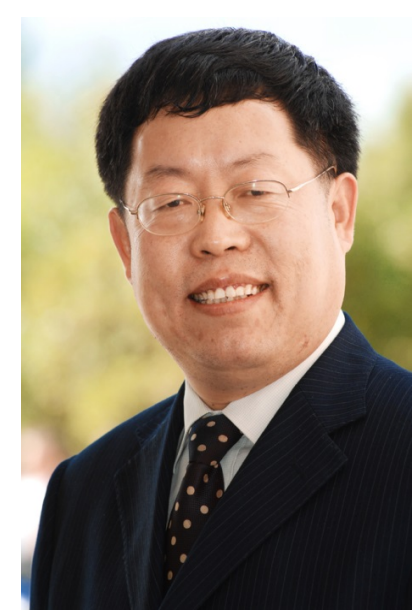

Can $\mathrm{Li}$

Professor

Editor-in-Chief,

Chinese Journal of Catalysis

Dalian Institute of Chemical Physics,

Chinese Academy of Sciences

E-mail: canli@dicp.ac.cn

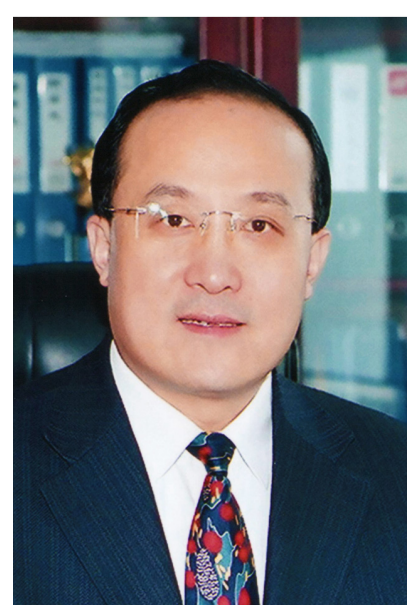

Tao Zhang

Professor

Editor-in-Chief,

Chinese Journal of Catalysis

Dalian Institute of Chemical Physics,

Chinese Academy of Sciences

E-mail: taozhang@dicp.ac.cn

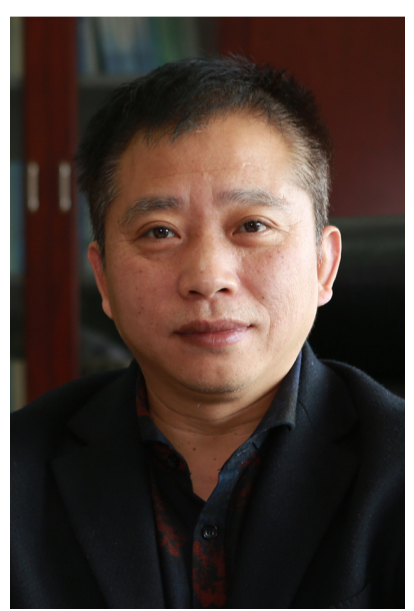

Zhongmin Liu

\section{Professor}

Director,

Dalian Institute of Chemical Physics,

Chinese Academy of Sciences

E-mail: zml@dicp.ac.cn
We sincerely thank the authors who made their contributions to this issue specially for the 70th anniversay celebration of DICP. We also thank all the anonymous reviewers for the time and endeavors they devoted to the success of this special issue. As the transaction of the Catalysis Society of China, Chinese Journal of Catalysis has developed significantly together with DICP and the catalysis communities in China over the past years. The journal also strives to attract and publish more novel and significant articles in catalysis and timely distribute them to the catalysis communities across the world aiming to play indispensable roles in connecting the Chinese Catalysis Society to the world and moving toward to a truly international journal. 